\title{
A REVIEW ON THE HEC-HMS RAINFALL-RUNOFF SIMULATION MODEL
}

\author{
SALIL SAHU ${ }^{1 *}$, S.K. PYASI ${ }^{1}$ \& R.V. GALKATE ${ }^{2}$ \\ ${ }^{1}$ Jawaharlal Nehru Krishi Vishwa Vidyalaya, Jabalpur., India \\ ${ }^{2}$ National Institute of Hydrology, Regional Centre, Bhopal, India
}

\begin{abstract}
There are various natural resources available on the earth; water is one of them that has its utility in agriculture, industries, household, and the survival of all living beings. Water plays an important part in the communal as well as economic development of the nation. Thus,development planning, in addition management of various resources of water isrequired to meet various water demands. The long-term, reliable and accurate historical flow or discharge data are of utmost importance in managing various resources of water. However, obtaining gauge discharge data has always been a challenge in the country as it is not possible to make measurements at every location in the river. Thus, Rainfall-Runoff modelling is one of the important tools which uses a set of known parameter data and appropriate mathematical equations to simulate flow record at the desired location. The number of hydrological models has been evolved for simulating runoff from the rainfall data in last 10 years i.e.HEC-HMS.HEC HMS is the hydrological model that has the capability of transforming rainfall into runoff. HEC HMS is frequently used rainfall runoff model, created by USACE, accessible in the free domain and can estimate Runoff from the Rainfall. The present paper reviews the studies carried out by researchers on the HEC-HMS model worldwide to ascertain its ability to simulate runoff with accuracy and to make use for decision-making. From the review, it could be summarised that many researchers. From the review, it could be seen that many researchers compared different modelling methods to obtain the best model suitable under different hydrological conditions and found HEC-HMS as a good model over others and recommended it for simulation of runoff. From the reviews, it was seen that the HEC-HMS rainfall-runoff model has a vast range of utility in flood forecasting and water resource planning and management. In most of the studies, HEC-HMS rainfall-runoff modelling was found efficient and reliable in different river basins to simulate runoff with accuracy. Thus, the model could be used for runoff simulation in an ungauged basin for water resources planning, development, management, and decisionmaking.
\end{abstract}

KEYWORDS: HEC-HMS, Rainfall-runoff Modelling, Simulation Model

Received: Jul 27, 2020; Accepted: Aug 17, 2020; Published: Sep 21, 2020; Paper Id.: IJASRAUG202024

\section{INTRODUCTION}

Arranging and the executives of water assets require a long-lasting record of verifiable stream information. "Since the runoff computation from ungauged or poorly gauged catchment is a serious challenge in developing countries like India where higher operation and maintenance costs differed gauging on small and medium rivers" (Jaiswal et al. 2020), the runoff must be anticipated utilizing the accessible precipitation information. "A model relates something unknown to estimate something known"(USACE-HEC 2000). On account of Rainfall-Runoff modelling, a Rainfall-Runoff model is utilized to assess the unknown runoff data by utilizing the known precipitation information. There is the quantity of Rainfall-Runoff models is accessible, one of them is - HEC-HMS. 
HEC-HMS is the computer application created underthe Research and Development Program of USACE and was first released by the Hydrologic Engineering Center (HEC) in 1992. The HEC-HMS can simulate the rainfall-runoff routing process both in common as well as in restrainedconditions. "The HEC-HMS is the replacement to and substitution for the Flood Hydrograph Package HEC-1 and different specific variants of HEC-1" (USACE-HEC 2000). The underlying arrival of HEC-HMS was called version1.0,it incorporated all the highlights of HEC-1 with some improvement.The second arrival of the program was version 2.0, which included SMA method that all-encompassing the program from event based to both continuous simulation \&event based.The third significant release of the programwas the version 3.0 that presented new graphical interface with the expansion of potential \& snowmelt evapotranspiration methods in the meteorological model, additionally some new methods were presented in basin model for infiltration representation. The fourth significant arrival of the program is version 4.0, that additional sediment transport \& surface erosion features in the computation. HEC-HMS 4.2.1 is the latest version of the HEC-HMS program. The HEC-HMS gives some extraordinary components to precipitation-runoff-routing simulation, for example, - precipitation-specification options, Loss models for assessing runoff volume, transform model for transforming excess rainfall, Hydraulic routing models for accounting storage and energy flux, the model for Baseflow and models of water control measures (including divergence and storage).

The HEC-HMS incorporates some extra program that were not accessible in HEC-1, for example, a distributed runoff model which can be utilized with the distributed precipitation data, a soil-moisture accounting method for simulating the longer term response of basin during wet and dry condition, an auto-calibration featurefor assessing model parameters dependent on the given hydro-meteorological condition. The outcomes acquired from HEC-HMS can be utilized for dissecting flood frequency, urban flooding, reservoir spillway capacity, flood warning system planning, stream restoration and so forth (USACE-HEC 2008). With certain points of interest, the HEC-HMS likewise has a few impediments,for instance, it cannot demonstrate model branching and looping stream network. Furthermore,it cannot be applied for modelling backwater in a stream network. This paper presents some of the reviews of the work done by different analysts utilizing HEC-HMS Rainfall-Runoff model for representing rainfall runoff processes occurring over the basins.

\section{HEC-HMS model}

Chu et al., (2009) directed both based as well as continuous rainfall runoff modelling utilizing the hydrological modelling system (HEC-HMS) for Mona lake catchment of west Michigan U.S. Initially event-based hydrological modelling was performed for four rainfall event and then these parameters were set utilizing calibration, and afterward these parameters were utilized for performing continuous modelling. The Soil Conservation Service-Curve Numbermodal and soil moisture accounting method were utilized as a loss model in the event and continuous hydrologic modelling. The Clark UH modalwas for transforming excess precipitation into direct hydrograph. The basin model was made, by utilizing the WMS model. The outcomes suggest the parameter identified during advancement of fine-scale event models show better outcomes in the coarse-scale continuous model.

Verma et al. (2009) computed rainfall runoff modelling utilizing theWEPP\&HEC-HMS rainfall runoff model for The Upper Baitarani River basin of Eastern India. They utilized day to day observed rainfall discharge datafrom June toOctober for the year1999 to 2005.The GIS techniques \&remote sensing were utilised for preparing slope map, soil map, LULC figure of the study area.The results uncovered that,for the year 1999,2002,2004 \& 2005 the simulated streamflow was less than the observed stream flow, and the simulated streamflow for the year 2003 and 2001 was higher than the 
observed stream flow for both WEPP \& HEC-HMS. But in 2000,the simulated stream flow was lesser in case of HECHMS and was higher in case of WEPP. The calibration and validation results indicate that the stream flow computed using HEC-HMS was more acceptable than that estimated using WEPP. Hence, at last we summarised that the HEC-HMS is better acceptable than WEPP for simulating discharge for Basin of Baitarani River.

Oleyiblo et al., (2010) set up a model to forecast the floods in theMisai and Wan'an catchments in Chinautilizing HEC-HMS model. HEC-Gehus tools in combination with Arc-GIS was utilized to make basin model, for estimation of infiltration losses ,the initial and constant model was utilised and for transformation of excess rainfall into direct runoff, the SCS UH was utilized. For modelling based flow trial recession model was utilized, the reaches were modelled using Muskingum routing model.The experimentation and error method were utilized for modifying parameters for calibrating the model physically. The auto calibration was utilized to verify the adequacy and suitability of the parameter values. The percentage error in the peak and volume was utilized during the optimization process. It is found from the investigation that the efficiency and suitability of a model cannot be decided by its structure and its complexity, however the structure of HEC-HMS has straight forward structure, and it isan integral asset for flood forecasting.

Majidi et al., (2012) performed Rainfall-Runoff modellingonthe Abnama basin in Iran using the HEC-HMS model. Used Green-Ampt method was utilised for loss estimation \&SCS unit hydrograph method was utilised for transforming excess rainfall into direct runoff Muskingum method was used for routing. Five Rainstorm events were taken for the examination. Calibration, validation, and sensitivity analysis was finished. The connectionof the observed and simulated discharge was discovered to be 0.89 which shows a solid match. Itfinished up the ability of the model for runoff simulation in the Abnana basin.

Halwatura et al., (2013) made an attempt to set a Rainfall-Runoff model by using HEC-HMS for the Attangalu Oya river basin situated in Sri Lanka.Theythought about various transform and loss method and found that the combination of Snyder unit hydrograph model for transforming excess precipitation into direct runoff and the deficit and constant method for lossestimation, givesmore dependable outcomes for Attangalu Oya river basin. Study recommends Snyder unit hydrograph is the better transforming method for Attangalu Oya basin, Sri Lanka with initial and constant method as Loss method.

Asadi et al., (2013) researched the Delibajak basin in Kohgoilpuye and Boyerahmad, Iran was first measured as a lumped and then split up into sub-basins and the Rainfall-Runoff model was created for both the case utilizing the HECHMS model separately, and the result was compared for both the cases. The SCS-CN method was taken as a loss method. Calibration and validation were performed for both the model and found as the semi-distributed model shows a better result. It is concluded from the study that the Semi-Distributed model shows better results than the Lumped model developed in HEC-HMS.

Rathod et al., (2015) made a lumped continuous hydrological model for assessing discharge for various precipitation events occurring over the three sub-catchments of Tapi river basin. utilized Green-ampt method as a loss method and compared at the SCS UHand Snyder UH for transformation of excess rainfall into direct runoff and found that the SCS unit hydrograph method gives better outcomes, additionally in sensitivity examination they found that the lag time and suction head are the most touchy parameter though impervious was the least sensitive parameter. It is closed from the investigation that optimization of the parameters should be possible with few trials if the catchment characteristics trademark is notable. 
Singh et al., (2015) utilised HEC-HMS hydrological model to setup a continuous model for Vamsadhara River basin. Based on the topography and land use pattern, the basin was divided into sub basin. The soil moisture accounting technique was utilized for setting HEC-HMS model. The observed rainfall runoff data, from 1984 to 1989 was used for calibrating the model and model was verified using the observed data from 1990 to 1993.The Performanceof the model during calibration wasacceptable (with 0.71 coefficient of determination value and 0.70 as NSE value);likewise,the performance of the model duringverification wasalso good (with $\mathrm{R}^{2}$ value as 0.78 and NSE value as 0.76 ). From the examination, it is concluded that the SMA method can be utilized to model streamflow in Vasundhara river basin, India

Sampath et al., (2015) performed continuous precipitation-discharge modelling using HEC-HMS for Deduru Oya riverbasin. The rainfall and discharge data in daily basis, with LULC and soil map the area research was utilized for the current research. The precipitation-excess was estimated using SMA method, while the discharge volume was computed using Clark UH model and recession model was utilized for base flow estimation. For the interval, from October to December1985 the calibrationwas done. For period October1984 to September 1985 and October1987 to September1989, the model validation was done. Hence, from the research, it is concluded that the HEC-HMS has enough potential for managing water in Deduru Oya river basin.

Azmat et al., (2017) compared the different loss and transform method available in HEC-HMS, for setting event based and continuous precipitation- discharge model for Jhelum river basin, India. The remotely sensed tropical rainfall measuring mission data was utilized for computing runoff. The value of curve number was identified using soil map and LULC of the study area. For period of 2000 to2007 the calibration was done, while for period from 2007 to 2012 the model validation was done. The result concluded that the Clark Unit Hydrograph transform method works well with green ampt loss method, for performing event-based simulation, while SMA works fine with Snyder UH, for continuous simulation in Jhelum `river basin.

Vishweshwaran et al., (2017) utilised HEC-HMS model for modelling the rainfall runoff process occurring over the Krishna river basin. He performed event-basedmodelling utilizingdaily rainfall. For this, the Soil Conservation ServiceCurve Number method for estimating losses and for transforming excess precipitation into a direct runoff hydrograph, The Soil Conservation Service unit hydrograph method was utilized. The model calibration was done for the monsoon period of 2011 and validation was done for the 2007 and 2013 monsoonperiod. In the statistical evaluation during calibration, it shows Nash coefficient of 0.353 and $\mathrm{R}^{2}$ estimation of $93.7 \%$ and during validation for 2007 it shows Nash coefficient value as 0.41 and $\mathrm{R}^{2}$ as $87.9 \%$, for 2013 Nash was 0.48 and $\mathrm{R}^{2}$ was $95.9 \%$.

Derdour et al., (2018) utilised HEC-HMS hydrological model for simulated runoff in the Ksour mountain's semiaridarea in Ain Sefra in South West Algeria.The loss rate was estimated utilizing SCS-CN method and the runoff rate was estimated using SCS unit Hydrograph method. Thecomputed peak discharge was exceptionally near the observed value during the calibration \& validation of model.

Haibo et al., (2018) modelled the precipitation runoff process of Huan river basin of China for flood forecasting by utilizing the HEC-HMS, ArcGIS was utilized to extract watershed information as per Digital Elevation Model data. The initial constant rate loss model was utilised to determine runoff volume, whilethe Synder unit line model was utilised to determine the direct runoff. Muskingum method was utilized for routing. The observed runoff data was used to calibrate and validate the developed model. The outcome demonstrated the satisfactory scope of coefficient of agreement\& determination. 
Darji et al., (2019)used HEC-HMS modelfor modelling the precipitation runoff process model for Machhu River basin Gujarat. For this 40-year rainfall, data was taken to estimate runoff and was related with the observed runoff data and the coefficient of determination value was found to be 0.89 , which is the acceptable prediction value. Basin model was made utilizing the HEC-GEOHMS tool in Arc-GIS software. HEC-DSS application was utilized to analyse the result.

Bhuiyan et al (2017) made an effort to set up precipitation- runoff model using soil water content data derived from RADARSET-2 satellite for forecasting the flood in the sturgeon creek catchment ( mainly dominated with snowmelt), by utilizing hydrologic engineering system. Both continuous and event modelling was conducted to check the adoptability of HEC -HMS for the research area. The computation results shows the good match of observed and computed flow hydrograph. The timing and amount of the snowmelt spring was also in acceptable range. The soil water content data was taken from fall soil moisture survey of Manitoba and was extracted from RADARSET -2, the inspection of the result obtained for both the cases displays that the data extracted from RADARSET -2, improved the modelling results. Hence, at last it is concluded that the RADARSET -2 derived soil moisture data improves the performing of the HEC-HMS.

Sampath et al., (2015) performed continuous precipitation-discharge modelling using HEC-HMS for Deduru Oya river basin. The rainfall and discharge data in daily basis, with LULC and soil map the area research was utilized for the current research. The precipitation-excess was estimated using SMA method, while the discharge volume was computed using Clark UH model and recession model was utilized for base flow estimation. For the interval, from October to December 1985 the calibrationwas done. For period October 1984 to September 1985 and October 1987 to September1989, the model validation was done. . Hence, from the research, it is concluded that the HEC-HMS has enough potential for managing water in Deduru Oya river basin.

Azmat et al., (2017) compared the different loss and transform method available in HEC-HMS, for setting event based and continuous precipitation- discharge model for Jhelum river basin, India. The remotely sensed tropical rainfall measuring mission data was utilized for computing runoff. The value of curve number was identified using soil map and LULC of the study area. For period of 2000 to2007 the calibration was done, while for period from 2007 to 2012 the model validation was done. The result concluded that the Clark Unit Hydrograph transform method works well with green ampt loss method, for performing event-based simulation, while SMA works fine with Snyder UH, for continuous simulation in Jhelum `river basin.

\section{CONCLUSIONS}

From the exhaustive review work carried out on the HEC-HMS rainfall-runoff model, it could be concluded that the selection of the modelling method and approach is mainly based on the desired output and availability of the data. Researchers compared different modelling methods to obtain the best model suitable under different hydrological conditions and found HEC-HMS as a good model over others and recommended it for simulation of runoff. From the reviews, the HEC-HMS rainfall-runoff model is a wide range of applications in flood forecasting and water resource planning and management this is concluded from our study. The use of the HEC-GeoHMS tool for basin model development and for obtaining basin characteristics was appreciated by many researchers. Some researchers found model parameters value by using equations, while some optimized it during calibration. Different researchers used different criteria for model calibration, some researchers used hourly data, while some used daily rainfall-runoff data for calibration. Most of the researchers used the auto-calibration technique available in HEC-HMS for calibrating the model. The model statistical evaluation was done using the various evaluation criteria available in HEC-HNS. In most of the HEC-HMS 
rainfall-runoff modelling studies, the efficiency value of NS was mostly found as 0.60 to 0.90 which indicates that the model is robust and capable to simulate runoff in best agreement with observed hydrograph in any watershed.

From the review of these papers, it can be concluded that the HEC-HMS has enough potential to simulate runoff with accuracy using rainfall and basin characteristics. It shows better results in a semi-distributed and distributed approach, the HEC-GeoHMS tool can be used for river basin model development and finding basin characteristics, the autocalibration and manual calibration both works better in HEC-HMS, the soil moisture accounting loss method work more accurately for continuous modelling. It can also be concluded that every model has its strength and some limitations hence model must be selected based on the end goal of the research.

\section{REFERENCES}

1. Asadi, A., 2013. Application of HEC-HMS for Flood Forecasting in Kabkian Basin and Delibajak Subbasin in Iran. IOSR J. Eng. 03, 10-6. https://doi.org/10.9790/3021-03931016.

2. Azmat.M et al., (2017). Application of HEC-HMS for the event and continuous simulation in highaltitude scarcely-gauged catchment under changing climate. European Water, 8.

3. Bhuiyan, H., McNairn, H., Powers, J., Merzouki, A., 2017. Application of HEC-HMS in a Cold Region Watershed and Use of RADARSAT-2 Soil Moisture in Initializing the Model. Hydrology 4, 9. https://doi.org/10.3390/hydrology4010009

4. Chu, X., Steinman, A., 2009. Event and Continuous Hydrologic Modeling with HEC-HMS. J. Irrig. Drain. Eng. 135, 119-124. https://doi.org/10.1061/(ASCE)0733-9437(2009)135:1(119)

5. Darji, K., Khokhani, V., Prakash, D.I., Mehmood, K., Pham, B.T., Final, M.E., 2019. Rainfall-Runoff Modelling Using HECHMS Model: An Application of Regression Analysis. Journal Emerg. Technol. Innov. Res. JETIR 6, 10.

6. Derdour, A.et al., (2018). Modelling rainfall runoff relations using HEC-HMS in a semi-arid region: A case study in Ain Sefra watershed, Ksour Mountains (SW Algeria). JOURNAL OF WATER AND LAND DEVELOPMENT, No. 36 (I-III): 45-55.

7. Yousuf, Abrar, et al. "Modelling runoff and sediment yield from a small forest watershed in Shivalik foot-hills using WEPP model." International Journal of Agricultural Science and Research 5.6 (2015): 67-78.

8. Halwatura, D., Najim, M.M.M., 2013. Application of the HEC-HMS model for runoff simulation in a tropical catchment. Environ. Model. Softw. 46, 155-162. https://doi.org/10.1016/j.envsoft.2013.03.006

9. Haibo, M. et al., (2018). Application of Synthetic Unit Hydrograph on HEC-HMS Model for flood forecasting. MATEC Web of Conferences 246.

10. Geetha, K., et al. "A Modified SCS-CN Based Model For Long Term Hydrologic Simulation." International Journal of Civil, Structural, Environmental and Infrastructure Engineering Research and Development (IJCSEIERD) ISSN (P) (2014): 22496866.

11. Jaiswal, R. K., et al., (2020). Comparative evaluation of conceptual and physical rainfall-runoff models. Applied Water Science, 10(1), 48. https://doi.org/10.1007/s13201-019-1122-6

12. Majidi, A., Shahedi, K., 2012. Rainfall-Runoff simulation, HEC-HMS, Green-Ampt, Abnama watershed, Iran. Int. J. Hydraul. Eng. 5. https://doi.org/10.5923/j.ijhe.20120101.02.

13. Oleyiblo, J.O., 2010. Application of HEC-HMS for flood forecasting in Misai and Wan'an catchments in China. Water Sci. Eng. 3, 9. https://doi.org/10.3882/j.issn.1674-2370.2010.01.002 
14. ADGOLIGN, TENA BEKELE, GVR SRINIVASA RAO, and YERRAMSETTY ABBULU."Assessment of spatio-temporal occurrence of water resources in Didessa Sub-basin, West Ethiopia." International Journal of Civil, Structural, Environmental and Infrastructure Engineering Research and Development (IJCSEIERD)(ISSN (P): 2249-6866; ISSN (E): 2249-7978) 5.1 (2015): 105-120.

15. Rathod, P., Borse, K., Manekar, V.L., 2015. Simulation of Rainfall - Runoff Process Using HEC-HMS (Case Study: Tapi River, India). Presented at the HYDRO 2015 INTERNATIONAL IIT Roorkee, India, 17-19 December, 2015 20th International Conference on Hydraulics, Water Resources and River Engineering, p. 10. https://www.researchgate.net/publication/291274149

16. Sampath, D.S., Weerakoon, S.B., Herath, S., 2015. HEC-HMS model for runoff simulation in a tropical catchment with intrabasin diversions - case study of the Deduru Oya river basin, Sri Lanka. Eng. J. Inst. Eng. Sri Lanka 48, 1. https://doi.org/10.4038/engineer.v48i1.6843

17. Tufa, DAMTEW FUFA, Y. E. R. R. A. M. S. E. T. T. Y. Abbulu, and G. V. R. Srinivasarao. "Watershed hydrological response to changes in land use/land covers patterns of river basin: A review." International Journal of Civil, Structural, Environmental and Infrastructure Engineering Research and Development 4 (2014): 157-170.

18. Singh, W.R., Jain, M.K., 2015. Continuous Hydrological Modeling using Soil Moisture Accounting Algorithm in Vamsadhara River Basin, India. J. Water Resour. Hydraul. Eng. 4, 398-408. https://doi.org/10.5963/JWRHE0404011

19. USACE-HEC (2000) Hydrologic modelling system HEC-HMS technical reference manual. US Army Corps of Engineers, Hydrologic Engineering Centre (HEC), Davis, USA

20. USACE-HEC (2008) Hydrologic modelling system HEC-HMS v3.2 user's manual. US Army Corps of Engineers, Hydrologic Engineering Center (HEC), Davis, US

21. Verma, A.K., Jha, M.K., Mahana, R.K., 2010. Evaluation of HEC-HMS and WEPP for simulating watershed runoff using remote sensing and geographical information system. Paddy Water Environ. 8, 131-144. https://doi.org/10.1007/s10333-0090192-8

22. Visweshwaran Ramesh, 2017. Application of the HEC-HMS model for runoff simulation in the Krishna basin. https://doi.org/10.13140/RG.2.2.13326.05448 

